\section{Another Munchausen?}

\section{DeAR SiRS}

I believe this account merits being widely known because further admissions seem likely with psychiatrists being involved.

A 21-year-old man presented in casualty saying he had taken 10 paracetamol tablets, 45 phenytoin tablets, a lot of alcohol and had injected an unknown substance. On admission to a medical ward he added that he had awallowed two razor blades and four nails. Radiography showed this to be so. Shortly afterwards he swallowed a ward thermometer which was shown to be broken and the mercury spilled at re-X-ray. During the night he claimed to hear voices instructing him, was noisy, abusive, uncooperative and assaulted a female nurse. A psychiatric opinion the next morning resulted in compulsory admission to the mental illness unit under Section 2 of the Mental Health Act.

He explained a fresh upper midline abdominal scar as resulting from a pyloroplasty for a bleeding ulcer and the phenytoin for lifelong epilepsy. The distressed state, which he said caused the ingestion of drugs and hardware, resulted he alleged from his girl friend leaving him, his mother being seriously ill with a heart attack and the recent death of his father. This history could not be verified because the addresses he gave for relatives proved false and his family doctor whose name and Scottish address he gave could not be found. He refused to disclose the hospital where the surgery had been done.

Following admission to the mental illness unit mood and behaviour rapidly became normal. The raxor blades, nails and thermometer glass passed per rectum as the surgical opinion had anticipated. The surgical team thought the upper midline scar may have resulted from exploratory surgery to treat a previous episode of swallowing sharp objects. The Poisons Unit advised the mercury would not cause harm. After three days the Section 2 was cancelled and the man discharged with plans to leave Southampton. He refused out-patient treatment.

This account suggests fabrication and the likelihood of further hospital attendance with similar conduct.

Royal South Hants Hospital

B. BARRAClOUgh Southampton SO9 4PE

\section{Academic sub departments - the way ahead for peripheral centres}

DEAR SIRS

19 October 1990 marked the opening by our College President, Professor A. Sims, of an Academic Sub Department of Psychological Medicine (University of Wales College of Medicine, Cardiff) based at the North Wales Hospital, Denbigh, Clwyd under the Director, Dr Greg Wilkinson and Deputy Director, Dr David Healy.

The development owes much to the vision of Professor Peter McGuffin, Department of Psychological Medicine, Cardiff and to the energy and commitment of Dr M. M. Tannahill, consultant psychiatrist, North Wales Hospital, whose tireless work played no small part in ensuring its success.

It is perhaps worthwhile remembering the multifunctional purpose of such a unit and the benefits (already much in evidence at the North Wales Hospital) that it bestows - in maintaining academic standards, providing a focus for clinical audit, facilitating research, stimulating reading and debate and upholding the library and literature search facilities, enhancing teaching and a continuing postgraduate educational programme, ensuring the probability of College accreditation of training posts, providing a suitable centre for the MRCPsych examination, attracting eminent visiting speakers from throughout the UK and ultimately enhancing recruitment of staff to training and service posts.

Moreover, this sub department is not only the embodiment of academic life but provides an ethos that pervades and rejuvenates the whole local establishment, thus ensuring its continuation as a centre of excellence.

Perhaps this is a model which is worthy of replication in settings where falling standards and subsequent staff shortages could be pre-empted.

Coed Du Hospital,

Rhydymwyn, near Mold, Clwyd

North Wales Hospital, Denbigh, Clwyd

Bryn y Neuadd Hospital, Llanfairfechan, Gwynedd

(see also Psychiatric Bulletin, January 1990, 15, 31-32).

\section{General practice liaison}

DEAR SIRS

In their engaging study of contacts between GPs and psychiatrists in Nottingham surgeries (Psychiatric Bulletin, October 1990, 14, 592-594), Darling \& Tyrer note that psychiatrists were initiating a higher proportion of the shorter contacts (lasting less than five minutes). They imply that this observation somehow runs counter to the suggestion (wrongly attributed to Wilson \& Wilson, 1985) that such contacts are less attractive to psychiatrists.

Clearly the duration of a contact can be determined only by the person who terminates it. There remains a possibility that the initiating psychiatrists would have preferred longer contacts. This point can easily be clarified, since the psychiatrists in question 
are none other than the authors themselves! By the same token, should it transpire that they prefer to talk about patients for less than five minutes, it does not follow that such brief conversations are generally felt to be adequate by colleagues.

What my wife and I actually drew attention to, was the danger that "these hurried conversations may be substituted for the often more thoughtful formulations which are encouraged by the process of writing a traditional referral letter". Darling \& Tyrer make a similar point when they acknowledge that sporadic contacts may be in danger of promoting a spurious sense of understanding. I would count it a sad day for psychiatry if general practice liaison resulted in large numbers of us "going native".

STEPHEN WILSON

University of $O x$ ford and

Ashhurst Clinic, Oxford OX44XN

\section{References}

DARLING, C. \& TYRER, P. (1990) Brief encounters in general practice: liaison in general practice psychiatry clinics. Psychiatric Bulletin, 14, 592-594.

Wilson, S. \& Wilson, K. (1985) Close encounters in general practice: experiences of a psychotherapy liaison team. British Journal of Psychiatry, 146, 277-281.

DeAr Sirs

Dr Wilson is strictly correct in pointing out that his article in 1985 did not state directly that short contacts with general practitioners in liaison psychiatry were less attractive to psychiatrists. However, the implication was given that such contacts were undesirable and readers can judge whether this view is reinforced in his letter. We did indeed record some subjective aspects of liaison, whether the contacts were felt to be useful to both the initiators and receivers of each contact, but were restrained by space in our paper.

Although most of the contacts $(94 \%)$ were judged to be of value to psychiatrists, general practitioners and other primary care team members, significantly more of the contacts initiated by GPs were not felt to be of value to the psychiatrist $\left(20 \% ; \chi^{2}=23.6\right.$, df 2 , $P<0.001)$. In interpreting this finding it is important to realise that all contacts initiated by psychiatrists were of patients referred to, or already in, psychiatric care, whereas many GP contacts were of patients treated entirely by the primary care team.

We are not advocating short contacts as an ideal form of liaison. It is not a satisfactory form of communication on its own, but when taken in the context of other forms of service can reinforce continuity of care and save considerable time. Above all, it allows the opportunity for liaison, clinical assessment and treatment to be part of a comprehensive primary care service that buttresses the resources available to the general practitioner and helps to reduce the need for hospital treatment (Tyrer et al, 1990). It is premature for Dr Wilson to conclude that 'going native', a phrase that is patronising to both psychiatrists and general practitioners, would be sad for psychiatry. In any case, we would rather be part of a primitive service that is valuable to patients than a sophisticated one that is ineffective.

\section{St James University Hospital \\ Leeds LS9 7TF}

Claire Darling

\section{Early Intervention Service}

St Charles Hospital

London W10 6DZ

\section{Reference}

TYreR, P., FergusOn, B. \& WADSWORTH, J. (1990) Liaison psychiatry in general practice: the comprehensive collaborative model. Acta Psychiatrica Scandinavica, 81, 359-363.

\section{Rotational training schemes}

DeAr SIRS

While sympathising with Drs Madden \& Lewis's concern about changes to current rotational training schemes with the implementation of Achieving a Balance, I would like to point out that there are some aspects of these new arrangements which will clearly benefit trainees (Psychiatric Bulletin, November $1990,14,681$ ).

Firstly, as they suggest, SHO appointments can easily be made for longer than one year to provide a job security for trainees while settling into a new career and undertaking the formal training required for MRCPsych Part I. The old SHO/registrar rotations within districts can remain but without the promotion to registrar.

Requiring Part I MRCPsych for promotion to career registrar brings psychiatry into line with other medical specialities, which in my view improves standards. It may also provide a point of entry for potential consultant psychiatrists and enables imaginative new rotations to be created at registrar level. While SHO rotations can remain within health districts, registrar rotations can be wider and interdistrict similar to those available in many regions for senior registrar training. A three or four year registrar rotation provides the continuing job security that is required for Part II MRCPsych training but also allows a wider clinical experience which may include access to sub-secialities not available in all districts.

While the creation of a further three year registrar rotation may appear to lengthen the time in training, 